\title{
Comparisons of ecorational and chemical insecticides against crucifer flea beetle (Coleoptera: Chrysomelidae) on canola
}

\section{Authors: Frank B. Antwi, D. L. Olson, and D. R. Carey}

This is a pre-copyedited, author-produced PDF of an article accepted for publication in

Economic Entogy following peer review. The version of record, *see citation beldw, is availablo online at: https://doi.org/10.1093/jee/100.4.1201.

Antwi, F. B., D. L. Olson and D. R. Carey. 2007. Comparisons of ecorational and chemical insecticides against crucifer flea beetle (Coleoptera: Chrysomelidae) on canola. Journal of Economic Entomology 100(4): 1201-1209. doi: 10.1093/jee/100.4.1201 


\title{
Comparisons of Ecorational and Chemical Insecticides Against Crucifer Flea Beetle (Coleoptera: Chrysomelidae) on Canola
}

\author{
F. B. ANTWI, ${ }^{1}$ D. L. OLSON ${ }^{2}{ }_{\text {AND D D. R. CAREY }}^{3}$
}

\begin{abstract}
Studies were done comparing the insecticides SpinTor (spinosad), BotaniGard (Beauveria bassiana), Neemix (azadirachtin), and Surround (kaolin, a clay) with conventional chemical insecticides Capture (bifenthrin) and Helix XTra (thiamethoxam), all applied at seven rates in a 7-d assay to assess their impact on adult crucifer flea beetle, Phyllotreta cruciferae (Goeze) (Coleoptera: Chrysomelidae). Lethal time (LT) required for 25, 50, and 75\% mortality $\left(\mathrm{LT}_{25}, \mathrm{LT}_{50}\right.$, and $\left.\mathrm{LT}_{75}\right)$ and relative potencies for the insecticide concentration groupings $(0$, $1 \mathrm{X}-1.5 \mathrm{X}$, and $2 \mathrm{X}-4 \mathrm{X}$ ) were estimated for each treatment by using survival functions. P. cruciferae mortality increased in response to increasing concentrations, especially for Helix XTra, Capture and SpinTor. After $2 \mathrm{~d}$ of exposure in 2002, mortality ranged from 54 to $78 \%$ for Helix XTra, from 60 to $94 \%$ for Capture, and from 66 to $92 \%$ for SpinTor across concentrations. In 2003, flea beetle mortality ranged from 37 to $60 \%$, from 29 to $63 \%$, and from 23 to $52 \%$ on exposure to Helix XTra, Capture, and SpinTor, respectively, for $2 \mathrm{~d}$. The $\mathrm{LT}_{50}$ and relative potencies of the insecticides were in the order of Helix XTra, Capture, and SpinTor $>$ BotaniGard, Neemix, and Surround. In 2002, $\mathrm{LT}_{50}$ values were 1 and $2 \mathrm{~d}$ for Capture and SpinTor, $2 \mathrm{~d}$ for BotaniGard, and $3 \mathrm{~d}$ for Neemix and Surround. In 2003, $\mathrm{LT}_{50}$ values occurred between 2 and $4 \mathrm{~d}$ after exposure to Helix XTra, Capture, and SpinTor, with $\mathrm{LT}_{50}$ values of 5-7 d on exposure to BotaniGard, Neemix, and Surround. SpinTor seems to be a suitable ecorational insecticide in canola, Brassica napus L., for $P$. cruciferae management.
\end{abstract}

KEY WORDS flea beetle, canola, insecticides, lethal time, relative potencies

The Northern Great Plains is the major canola (Brassica napus L.)-producing region in North America. Canada accounts for $>4.5 \mathrm{M}$ ha (Canola Council of Canada 2005), and a little $>469,000$ ha of canola is grown in the United States (USDA-NASS 2005a, 2005b, 2006). The crucifer flea beetle, Phyllotreta cruciferae (Goeze) (Coleoptera: Chrysomelidae), is an economically important insect pest of canola in the Northern Great Plains (Brown 1967, Burgess 1977, Lamb 1984, Thomas 2003).

Adult flea beetles emerge from overwintering sites in the spring as air temperatures warm to $14.7-$ $20^{\circ} \mathrm{C}$ (Lamb 1983). Overwintered adults initially feed on brassicaceous weeds, and then they move into canola fields as the crop emerges. They immediately begin to feed on young cotyledons and leaves (Lamb 1988). Feeding by this spring population of adults can reduce newly emerged plant stands within a few days (Burgess 1977). A new generation of adult flea beetles (i.e., the summer

\footnotetext{
${ }^{1}$ Corresponding author: Department of Land Resources and Environmental Sciences, Montana State University, Bozeman, MT 59717 (e-mail: frank.antwi@montana.edu).

${ }^{2}$ North Dakota Department of Agriculture and Department of Entomology, North Dakota State University, Fargo, ND 58105.

${ }^{3}$ Department of Entomology, North Dakota State University, Fargo, ND 58105.
}

population) can be found in canola feeding on the epidermis of stems, leaves, and pods during pod development (Burgess 1977, Thomas 2003). Adult crucifer flea beetle feeding on canola seedlings accounts for the greatest crop loss attributed to this pest; however, feeding injury during the pod stage does not cause economic damage during most years (Putnam 1977, Lamb and Turnock 1982, Lamb 1984, Weiss et al. 1991, Berglund and Mckay 2002).

Chemical insecticides are the first line of defense to protect the canola crop from crucifer flea beetle feeding injury in the spring (Lamb 1988). Most canola acres are planted with insecticide-treated seed, because there is no method available for predicting the occurrence of economically spring flea beetle densities (Canola Council of Canada 2000, Glogoza et al. 2002, Thomas 2003). Foliar chemical insecticides applied in response to crucifer flea beetle populations also can be effective when treatments are applied at an economic threshold of $25 \%$ feeding injury to cotyledons and first true leaves (Weiss et al. 1991).

There has been a shift in agricultural production toward development of environmentally friendly pesticides with the goal of maintaining cost-effective control. "Ecorational" insecticides are effective against many insect pests (Hajek et al. 1987, Miran- 
Table 1. Insecticide treatments and application rates

\begin{tabular}{lcccccrr}
\hline \multirow{2}{*}{\multicolumn{1}{c}{ Treatment $^{a}$}} & \multicolumn{7}{c}{ Rate of application $^{b}$} \\
\cline { 2 - 7 } & \multicolumn{1}{c}{$1 \mathrm{X}$} & $1.5 \mathrm{X}$ & $2 \mathrm{X}$ & $2.5 \mathrm{X}$ & $3 \mathrm{X}$ & $3.5 \mathrm{X}$ \\
\hline BotaniGard ES (ml/liter) & 0.51 & 0.77 & 1.02 & 1.28 & 1.53 & 1.79 \\
SpinTor 2SC (ml/liter) & 0.13 & 0.19 & 0.25 & 0.32 & 0.38 & 0.44 & 2.04 \\
Neemix 4.5EC (ml/liter) & 0.13 & 0.19 & 0.25 & 0.32 & 0.38 & 0.44 & 0.51 \\
Surround WP (g/liter) & 3.06 & 4.59 & 6.12 & 7.6 & 9.17 & 10.70 & 12.23 \\
Capture 2EC (ml/liter) & 0.04 & 0.06 & 0.08 & 0.10 & 0.12 & 0.14 \\
Helix XTra (mg/6.8 g seed) & 52 & 77 & 102 & 127 & 152 & 177 & 202 \\
\hline
\end{tabular}

${ }^{a}$ Treatments BotaniGard, SpinTor, Neemix, and Surround are ecorational insecticides, whereas Capture and Helix XTra are conventional synthetic insecticides.

${ }^{b}$ Rate of application: $1 \mathrm{X}$, field application rate; $1.5 \mathrm{X}, 1.5$ times the field application rate; $2 \mathrm{X}, 2$ times the field application rate; $2.5 \mathrm{X}, 2.5$ times the field application rate; $3 \mathrm{X}, 3$ times the field application rate, $3.5 \mathrm{X}, 3.5$ times the field application rate; and $4 \mathrm{X}$, 4 times the field application rate.

puri and Khachatourians 1995, Sparks et al. 1999, Thompson et al. 1999, McLeod et al. 2002, Gaugler 2004), and they may have potential for crucifer flea beetle management. Products of Bacillus thuringiensis spp. aizawai encapsulated $\delta$-endotoxin are recommended against cabbage white butterflies (Pieris spp.) and diamondback moth, Plutella xylostella (L.), in oilseed rape and other Brassica spp. (Eldelson et al. 1993, Hokkanen et al. 2003). Immaraju (1998) reported susceptibility of some flea beetles (i.e., Epitrix spp.) to azadirachtin, a plant defense chemical.

Ecorational insecticides are materials that are ecologically rational, with minimal or no adverse effects on other non target organisms or the environment (Ware 1989). They have unique modes of action compared with traditional insecticide chemistries, and some materials can play an important role in environmental conservation as well as insecticide resistance management. Spinosyns have unique molecular structure, potency at par with existing chemistries and a novel mode of action (Sparks et al. 2001). Spinosyns affect nicotinic and $\gamma$-aminobutyric acid receptors through an undetermined mechanism that underlies insecticidal properties of the spinosyns (Sparks et al. 2001, Thompson et al. 2000). Spores of entomopathogenic fungi attach to insect cuticle, germinate, and penetrate the body wall by using mechanical pressure, proteases, and chitinases (Thacker 2002). Multiplication of fungal spores within the body cavity causes insect death (Thacker 2002). Kaolin clay particle creates a film, or particle on plant surfaces that produces an unfamiliar and hostile environment that irritates and repels the insect, leading to reduction in feeding and oviposition (USDA 1998). Azadirachtins have antifeedant action (Blaney et al. 1990, Schmutterer 1990), and they alter ecdysteroid and juvenile hormone titers (Mordue et al. 1998, Barken and Stark 1997), resulting in growth regulatory effects.

Before the research reported here, ecorational insecticides have not been tested for crucifer flea beetle control in canola. The objective of this research was to determine the potential of ecorational insecticides, including a spinosyn; azadirachtin, an insect fungal pathogen; and kaolin for P. cruciferae management in canola.

\section{Materials and Methods}

In a leaf dip bioassay using modified methods of McLeod et al. (2002), SpinTor 2 SC (spinosad, Dow Agrosciences, Indianapolis, IN), BotaniGard ES (Beauveria bassiana, Emerald BioAgriculture Corp. Lansing, MI), Surround WP (kaolin clay, Engelhard Corp., Iselin, NJ), and Neemix 4.5 EC (azadirachtin, Certis USA, L.L.C., Columbia, MD) were compared with two conventional synthetic insecticides, Capture 2 EC (bifenthrin, FMC Corp., Princeton, NJ) and Helix XTra (thiamethoxam, Syngenta Crop Protection Inc., Greensboro, NC), for lethal time (LT) values and relative efficacies against adult $P$. cruciferae. These insecticides were chosen due to their modes of action and also to assess the possibility of their inclusion in resistance management strategy for $P$. cruciferae. The bioassay was conducted during the cotyledon stage of canola hybrid Roundup Ready (357 RR) grown in a greenhouse as follows. Nontreated canola seeds and seeds treated with Helix XTra were sown into plastic trays ( 26 by 26 $\mathrm{cm}$ ) containing Sunshine LCl Mix potting soil (Sun Gro Horticulture Inc., Bellevue, WA). Potting media were watered daily. Five days after plant emergence, cotyledons from nontreated seeds were excised from plant stems and dipped individually into petri dishes containing an insecticide treatment. Cotyledons were allowed to air dry for $10 \mathrm{~min}$. The commercial formulation of each insecticide was tested at seven concentrations $(1,1.5,2,2.5,3,3.5$, and 4 times the lowest label application rate; Table 1). A water treatment served as the control. Two adult flea beetles, along with a treated cotyledonstage seedling, were placed into individual glass vials $\left(5 \mathrm{~cm}^{3}\right)$ with a strip of germinating paper moistened with $0.030 \mathrm{ml}$ of water. Treatment vials were placed in an environmental chamber $(25 \pm$ $0.5^{\circ} \mathrm{C}$ and a photoperiod of $16: 8$ [L:D] h). Ten flea beetles in five vials were used per treatment, and concentration replicate, and each treatment con- 
Table 2. Time-concentration-mortality response of $P$. cruciferae to ecorational and chemical insecticides on cotyledon canola, 2002

\begin{tabular}{|c|c|c|c|c|c|c|c|c|}
\hline \multirow{2}{*}{ Treatment } & \multirow{2}{*}{$\mathrm{DAT}^{a}$} & \multicolumn{7}{|c|}{ 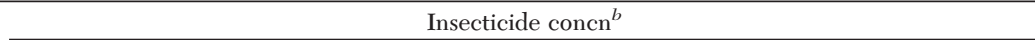 } \\
\hline & & $1 X$ & $1.5 \mathrm{X}$ & $2 \mathrm{X}$ & $2.5 \mathrm{X}$ & $3 \mathrm{X}$ & $3.5 \mathrm{X}$ & $4 \mathrm{X}$ \\
\hline & & \multicolumn{7}{|c|}{$\%$ mortality $^{c}$} \\
\hline BotaniGard ES & 1 & 18.1 & 31.5 & 18.9 & 23.7 & 36.8 & 31.2 & 28.2 \\
\hline Surround WP & 1 & 2.8 & 6.9 & 8.1 & 19.7 & 13.2 & 18.2 & 8.5 \\
\hline Neemix $4.5 \mathrm{EC}$ & 1 & 13.9 & 8.2 & 10.8 & 18.4 & 22.4 & 19.5 & 8.5 \\
\hline SpinTor 2SC & 1 & 41.7 & 50.7 & 48.6 & 61.8 & 60.5 & 71.4 & 78.9 \\
\hline Capture 2EC & 1 & 44.4 & 60.3 & 60.8 & 69.7 & 75.0 & 74.0 & 77.5 \\
\hline Helix XTra & 1 & 33.3 & 57.5 & 50.0 & 50.0 & 47.4 & 54.5 & 47.9 \\
\hline Control $^{d}$ & 1 & 0.0 & 0.0 & 0.0 & 0.0 & 0.0 & 0.0 & 0.0 \\
\hline BotaniGard ES & 2 & 29.2 & 45.0 & 57.1 & 51.8 & 41.1 & 45.1 & 40.0 \\
\hline Surround WP & 2 & 17.2 & 16.7 & 16.1 & 14.3 & -10.2 & 5.9 & -14.0 \\
\hline Neemix $4.5 \mathrm{EC}$ & 2 & 8.6 & 11.7 & 26.8 & 28.6 & 18.4 & 23.5 & 10.0 \\
\hline SpinTor 2SC & 2 & 65.5 & 71.7 & 80.4 & 82.1 & 73.5 & 90.2 & 92.0 \\
\hline Capture 2EC & 2 & 60.3 & 80.0 & 80.4 & 83.9 & 91.8 & 92.2 & 94.0 \\
\hline Helix XTra & 2 & 53.5 & 61.7 & 64.3 & 58.9 & 65.3 & 78.4 & 62.0 \\
\hline Control & 2 & 0.0 & 0.0 & 0.0 & 0.0 & 0.0 & 0.0 & 0.0 \\
\hline BotaniGard ES & 3 & 64.4 & 65.0 & 69.4 & 78.6 & 83.3 & 78.1 & 67.6 \\
\hline Surround WP & 3 & 35.6 & 5.0 & 5.6 & 14.3 & 19.4 & 0.0 & -14.0 \\
\hline Neemix $4.5 \mathrm{EC}$ & 3 & 24.4 & 15.0 & 22.2 & 38.1 & 8.3 & 6.3 & 16.2 \\
\hline SpinTor 2SC & 3 & 68.9 & 75.0 & 80.6 & 85.7 & 86.1 & 87.5 & 89.2 \\
\hline Capture 2EC & 3 & 68.9 & 85.0 & 94.4 & 88.1 & 94.4 & 93.7 & 97.3 \\
\hline Helix XTra & 3 & 62.2 & 72.5 & 72.2 & 76.2 & 61.1 & 78.1 & 73.0 \\
\hline Control & 3 & 0.0 & 0.0 & 0.0 & 0.0 & 0.0 & 0.0 & 0.0 \\
\hline BotaniGard ES & 4 & 77.1 & 80.6 & 92.3 & 97.0 & 100.0 & 93.1 & 79.3 \\
\hline Surround WP & 4 & 42.8 & 33.3 & 30.8 & 42.4 & 51.7 & 31.0 & 10.3 \\
\hline Neemix $4.5 \mathrm{EC}$ & 4 & 48.6 & 75.0 & 76.9 & 78.8 & 72.4 & 58.6 & 55.2 \\
\hline SpinTor 2SC & 4 & 80.0 & 97.2 & 96.2 & 97.0 & 89.7 & 89.7 & 96.6 \\
\hline Capture 2EC & 4 & 85.7 & 97.2 & 96.2 & 97.0 & 96.6 & 100.0 & 100.0 \\
\hline Helix XTra & 4 & 80.0 & 77.8 & 65.4 & 75.8 & 89.7 & 86.2 & 72.4 \\
\hline Control & 4 & 0.0 & 0.0 & 0.0 & 0.0 & 0.0 & 0.0 & 0.0 \\
\hline BotaniGard ES & 5 & 89.7 & 81.8 & 95.0 & 95.2 & 100.0 & 100 & 82.4 \\
\hline Surround WP & 5 & 55.2 & 36.4 & 45.0 & 47.6 & 72.7 & 22.2 & 41.2 \\
\hline Neemix $4.5 \mathrm{EC}$ & 5 & 44.8 & 22.7 & 50.0 & 52.4 & 31.8 & 16.7 & 47.1 \\
\hline SpinTor 2SC & 5 & 89.7 & 100.0 & 100.0 & 100.0 & 90.9 & 94.4 & 100.0 \\
\hline Capture 2EC & 5 & 96.6 & 95.5 & 95.0 & 100.0 & 95.5 & 100.0 & 94.1 \\
\hline Helix XTra & 5 & 96.6 & 90.9 & 100.0 & 90.5 & 90.9 & 94.4 & 76.5 \\
\hline Control & 5 & 0.0 & 0.0 & 0.0 & 0.0 & 0.0 & 0.0 & 0.0 \\
\hline BotaniGard ES & 6 & 91.3 & 93.8 & 100.0 & 100.0 & 100.0 & 100.0 & 90.9 \\
\hline Surround WP & 6 & 65.2 & 75.0 & 71.4 & 44.4 & 53.3 & 53.3 & 36.4 \\
\hline Neemix $4.5 \mathrm{EC}$ & 6 & 43.5 & 56.3 & 71.4 & 33.3 & 40.0 & 46.7 & 18.2 \\
\hline SpinTor 2SC & 6 & 95.7 & 100.0 & 100.0 & 100.0 & 93.3 & 100.0 & 90.9 \\
\hline Capture 2EC & 6 & 91.3 & 93.8 & 92.9 & 100.0 & 93.3 & 100.0 & 90.9 \\
\hline Helix XTra & 6 & 95.7 & 81.3 & 85.7 & 88.9 & 86.7 & 100.0 & 81.8 \\
\hline Control & 6 & 0.0 & 0.0 & 0.0 & 0.0 & 0.0 & 0.0 & 0.0 \\
\hline BotaniGard ES & 7 & 90.9 & 90.0 & 100.0 & 83.3 & 100.0 & 100.0 & 88.9 \\
\hline Surround WP & 7 & 90.9 & 100.0 & 100.0 & 50.0 & 75.0 & -66.7 & 55.6 \\
\hline Neemix $4.5 \mathrm{EC}$ & 7 & 36.4 & 100.0 & 87.5 & 33.3 & 37.5 & 0.0 & 66.7 \\
\hline SpinTor 2SC & 7 & 100.0 & 90.0 & 100.0 & 100.0 & 100.0 & 100.0 & 100.0 \\
\hline Capture 2EC & 7 & 100.0 & 100.0 & 100.0 & 100.0 & 100.0 & 100.0 & 100.0 \\
\hline Helix XTra & 7 & 100.0 & 100.0 & 100.0 & 100.0 & 87.5 & 100.0 & 100.0 \\
\hline Control & 7 & 0.0 & 0.0 & 0.0 & 0.0 & 0.0 & 0.0 & 0.0 \\
\hline
\end{tabular}

${ }^{a}$ DAT, days after treatment.

${ }^{b}$ Insecticide concn: 1X the lowest label application rate equals BotaniGard, $0.51 \mathrm{ml} /$ liter; Surround, $3.06 \mathrm{~g} /$ liter; Neemix, 0.13 ml/liter; SpinTor, $0.13 \mathrm{ml} /$ liter; Capture, $0.04 \mathrm{ml} /$ liter; and Helix XTra, $52 \mathrm{mg} / 6.8 \mathrm{~g}$ seed.

${ }^{c}$ Flea beetle mortality was adjusted for natural mortality in the control treatment; a negative value indicates that natural mortality was greater in the control than the treatment.

${ }^{d}$ Control, water treatment; mortalities were $0 \%$ after adjusted control mortality.

sisted of eight replicates in each of two trials. Trials 1 and 2 were run in 2002 and 2003, respectively. A nontreated canola field was monitored closely for the summer adult population, and beetles were collected with a sweep net immediately upon emergence and starved for $24 \mathrm{~h}$ before exposing them to treated seedlings. Beetle mortality via visual counting was recorded daily in each treatment. The number of dead individuals per vial was assessed daily for
1 wk. Flea beetles that did not move when carefully prodded with a forceps were considered dead.

Time-concentration-mortality response was assessed for each insecticide. Abbott's formula (Abbott 1925) as defined by Perry et al. (1998) was used to adjust for control mortality. Survival analysis was used to analyze the data to determine the lethal times for 25,50 , and $75 \%$ mortality $\left(\mathrm{LT}_{25}, \mathrm{LT}_{50}\right.$, and $\left.\mathrm{LT}_{75}\right)$ at each concentration grouping (1X-1.5X and $2 \mathrm{X}-4 \mathrm{X})$. 
Table 3. Lethal time for ecorational and chemical insecticides at 25,50 , and $75 \%$ mortality of $P$. cruciferae, 2002

\begin{tabular}{|c|c|c|c|c|c|c|c|c|c|c|c|c|}
\hline \multirow{3}{*}{ Treatment } & \multicolumn{12}{|c|}{ Concn level $^{a}$} \\
\hline & \multicolumn{2}{|c|}{$1 \mathrm{X}-1.5 \mathrm{X}$} & \multicolumn{2}{|c|}{$2 \mathrm{X}-4 \mathrm{X}$} & \multicolumn{2}{|c|}{$1 \mathrm{X}-1.5 \mathrm{X}$} & \multicolumn{2}{|c|}{$2 \mathrm{X}-4 \mathrm{X}$} & \multicolumn{2}{|c|}{$1 \mathrm{X}-1.5 \mathrm{X}$} & \multicolumn{2}{|c|}{$2 \mathrm{X}-4 \mathrm{X}$} \\
\hline & $\mathrm{Day}^{b}$ & $95 \% \mathrm{CI}^{c}$ & Day & $95 \% \mathrm{CI}$ & Day & $95 \% \mathrm{CI}$ & Day & $95 \% \mathrm{CI}$ & Day & $95 \% \mathrm{CI}$ & Day & $95 \% \mathrm{CI}$ \\
\hline & \multicolumn{4}{|c|}{$\mathrm{LT}_{25}{ }^{d}$} & \multicolumn{4}{|c|}{$\mathrm{LT}_{50}{ }^{d}$} & \multicolumn{4}{|c|}{$\mathrm{LT}_{75}{ }^{d}$} \\
\hline BotaniGard ES & 1 & $\mathrm{ND}^{e}$ & 1 & ND & 2 & ND & 2 & ND & 3 & ND & 3 & ND \\
\hline Surround WP & 2 & ND & 2 & ND & 3 & $3-4$ & 3 & ND & 5 & $4-5$ & 4 & ND \\
\hline Neemix 4.5EC & 2 & ND & 2 & $1-2$ & 3 & $3-4$ & 3 & $2-3$ & 4 & ND & 4 & ND \\
\hline SpinTor 2SC & ND & ND & 2 & ND & ND & ND & 2 & $1-2$ & ND & ND & 2 & $2-3$ \\
\hline Capture 2EC & 1 & ND & 2 & ND & 1 & ND & 1 & ND & 2 & ND & 2 & $1-2$ \\
\hline Helix XTra & ND & ND & ND & ND & ND & ND & ND & ND & ND & ND & ND & ND \\
\hline Controlf & 3 & ND & & & 3 & $3-4$ & & & 5 & $4-6$ & & \\
\hline
\end{tabular}

${ }^{a} 1 \mathrm{X}-1.5 \mathrm{X}$ and $2 \mathrm{X}-4 \mathrm{X}$ concn groups, respectively, equal BotaniGard, 0.51-0.77 and 1.02-2.04 ml/liter; Surround, 3.06-4.59 and 6.12-10.70 g/ liter; Neemix, 0.13-0.19 and 0.25-0.51 ml/liter; SpinTor, 0.13-0.19 and 0.25-0.51 ml/liter; Capture, 0.04-0.06 and 0.08-0.16 ml/liter; and Helix XTra, 52-77 and 102-202 mg/6.8 g seed. The Kaplan-Meier method was used in estimating lethal times for each concentration group.

${ }^{b}$ Day, lethal time in days.

${ }^{c} \mathrm{CI}$, confidence interval.

${ }^{d}$ Lethal time required for 25,50 , and $75 \%$ mortality.

${ }^{e} \mathrm{ND}$, no data; lethal time for percentile and confidence interval could not be estimated because the frequency value was $<1$ and exact lethal time was unknown.

${ }^{f}$ Control, water treatment.

Survival functions were estimated by using the Kaplan-Meier method (SAS Institute 2003) with the following model.

$$
\begin{gathered}
S(t)=\prod_{j: t_{j} \leq t}\left[1-\frac{d_{j}}{n_{j}}\right] \text { for } t_{1} \leq t \leq t_{k} \text { where } \\
{\left[1-\frac{d_{j}}{n_{j}}\right]=\text { the conditional probability of surviving }}
\end{gathered}
$$

to time $t_{\mathrm{j}+1}$, given that the individual has survived to time $t_{\mathrm{j}} . S(t)$ is the probability that an event time is greater than $t$. Kaplan-Meier method estimated the lethal times. The relative potencies for the insecticides were compared using the lethal times according to the method by Marcus and Eaves (2000).

\section{Results}

2002. Day 1. Mortality of P. cruciferae adults after exposure was greater in beetles exposed to the conventional chemical insecticides than BotaniGard, Neemix and Surround across the concentrations tested (Table 2). Mortality ranged from 33.3 to $77.5 \%$ after crucifer flea beetle was exposed to the conventional insecticides and from 41.7 to 78.9 after exposure to SpinTor. Among the ecorationals, SpinTor treatments resulted in greater levels of mortality compared with Helix $\mathrm{XTra}$, except at the $1.5 \mathrm{X}$ and $2 \mathrm{X}$ concentrations of SpinTor. Capture caused the greater mean mortality than any concentration of Helix XTra and all but the $4 \mathrm{X}$ concentration of SpinTor.

Day 2. Mortality continued to be greater in P. cruciferae exposed to the conventional insecticides and SpinTor (Table 2). Mortality ranged from 53.5 to $94 \%$ for the conventional insecticides and from 65.5 to $92 \%$ for SpinTor. Mortality ranged from 53.5 to $78.4 \%$ after exposure to Helix XTra treatments compared with from 60.3 to $94 \%$ for Capture and from 65.5 to $92 \%$ for SpinTor.

Day 3. P. cruciferae mortality ranged from 61.1 to 97.3\% for the conventional insecticides and from 64.4 to $89.2 \%$ for SpinTor and BotaniGard among the ecora- tional treatments (Table 2). Capture caused greater levels of mortality than SpinTor except at the IX rate. Only $1.5 \mathrm{X}$ and $2 \mathrm{X}$ concentrations of Helix XTra had a greater mortality effect compared with BotaniGard.

Day 4. Mortality ranged from 65.4 to $100 \%$ when the insect was exposed to the conventional insecticide treatments and from 77.1 to $100 \%$ for SpinTor and BotaniGard (Table 2). SpinTor and BotaniGard caused greater levels of mortality on P. cruciferae compared with Helix XTra, except at IX and 3X rates of SpinTor and IX rate of BotaniGard. Capture had a higher mortality effect on P. cruciferae compared with SpinTor except at $1.5 \mathrm{X}-2.5 \mathrm{X}$ concentrations.

Day 5. The conventional chemical insecticides resulted in 76.5-100\% mortality, whereas SpinTor and BotaniGard resulted in 81.8-100\% mortality (Table 2). However, there was no consistent pattern of differences in P. cruciferae mortality among these insecticide treatments.

Day 6. P. cruciferae mortality ranged from 81.3 to $100 \%$ for the conventional chemical insecticides and from 90.9 to $100 \%$ for SpinTor and BotaniGard (Table 2 ). When comparisons are made across the chemical insecticides and SpinTor and BotaniGard treatments, flea beetle mortality was consistently lower in the Helix XTra treatments except at IX and 3.5X concentrations.

Day 7. The mortality of $P$. cruciferae ranged from 87.5 to $100 \%$ for the conventional insecticides and from 83.3 to $100 \%$ for SpinTor and BotaniGard (Table 2 ). There was no consistent pattern of differences in flea beetle mortality among these treatments except at $1 \mathrm{X}, 2.5 \mathrm{X}$, and $4 \mathrm{X}$ rates of BotaniGard.

Lethal times for 25,50 , and $75 \%$ mortality was estimated for two concentration groups, for each insecticide tested against $P$. cruciferae (Table 3). The $\mathrm{LT}_{25}$ occurred at $1 \mathrm{~d}$ for Capture and BotaniGard and at $2 \mathrm{~d}$ for SpinTor, Neemix, and Surround for the two concentration groups (Table 3). Lethal time for $50 \%$ mortality of P. cruciferae was $1 \mathrm{~d}$ for Capture, $2 \mathrm{~d}$ for 
Table 4. Analysis and comparison of the efficacies of ecorationals to a standard chemical insecticide at 25, 50, and $75 \%$ mortality of $\boldsymbol{P}$. cruciferae, 2002

\begin{tabular}{lcccccc}
\hline \hline \multirow{2}{*}{ Treatment $^{a}$} & \multicolumn{5}{c}{ Concn level $^{b}$} \\
\cline { 2 - 7 } & $1 \mathrm{X}-1.5 \mathrm{X}$ & $2 \mathrm{X}-4 \mathrm{X}$ & $1 \mathrm{X}-1.5 \mathrm{X}$ & $2 \mathrm{X}-4 \mathrm{X}$ & $1 \mathrm{X}-1.5 \mathrm{X}$ & $2 \mathrm{X}-4 \mathrm{X}$ \\
\hline \multirow{2}{*}{ BotaniGard ES } & $\mathrm{LT}_{25 ; \mathrm{S}} / \mathrm{LT}_{25 ; \mathrm{T}}{ }^{c}$ & $\mathrm{LT}_{50 ; \mathrm{S}} / \mathrm{LT}_{50 ; \mathrm{T}}{ }^{c}$ & $\mathrm{LT}_{75 ; \mathrm{S}} / \mathrm{LT}_{75 ; \mathrm{T}}{ }^{c}$ \\
Surround WP & 0.5 & 2.0 & 0.5 & 0.5 & 0.7 & 0.7 \\
Neemix 4.5EC & 0.5 & 1.0 & 0.3 & 0.3 & 0.4 & 0.5 \\
SpinTor 2SC & $\mathrm{ND}^{d}$ & 1.0 & 0.3 & 0.3 & 0.5 & 0.5 \\
Capture 2EC & 1.0 & 1.0 & $\mathrm{ND}$ & 0.5 & $\mathrm{ND}$ & 1.0 \\
Helix XTra & $\mathrm{ND}$ & $\mathrm{ND}$ & $\mathrm{ND}$ & $\mathrm{ND}$ & $\mathrm{ND}$ & $\mathrm{ND}$ \\
Control $^{e}$ & 0.3 & 0.3 & 0.3 & 0.3 & 0.4 & 0.4 \\
\hline
\end{tabular}

${ }^{a}$ Treatment, Capture 2 EC was used as the standard chemical by which all treatments were compared, because the lethal time could not be estimated for Helix XTra the standard treatment.

${ }^{b} 1 \mathrm{X}-1.5 \mathrm{X}$ and $2 \mathrm{X}-4 \mathrm{X}$ concn groups, respectively, equal BotaniGard, 0.51-0.77 and 1.02-2.04 ml/liter; Surround, 3.06-4.59 and 6.12$10.70 \mathrm{~g} /$ liter; Neemix, $0.13-0.19$ and $0.25-0.51 \mathrm{ml} /$ liter; SpinTor, 0.13 0.19 and $0.25-0.51 \mathrm{ml} /$ liter; Capture, $0.04-0.06$ and $0.08-0.16 \mathrm{ml} /$ liter; and Helix XTra, 52-77 and 102-202 mg/6.8 g seed.

${ }^{c}$ Ratios of the lethal times of standard chemical to the treatments at 25,50 , and $75 \%$ mortality.

${ }^{d} \mathrm{ND}$, no data; ratio could not be estimated because the frequency values for lethal time estimation was $<1$ and exact lethal time was unknown.

${ }^{e}$ Control, water treatment.

SpinTor and BotaniGard, and $3 \mathrm{~d}$ for Surround and Neemix. The lethal time required for $75 \%$ P. cruciferae mortality was $2 \mathrm{~d}$ for Capture and SpinTor, $3 \mathrm{~d}$ for BotaniGard, $4 \mathrm{~d}$ for Neemix, and 4 and $5 \mathrm{~d}$ for Surround. For the concentration groups and insecticides with no lethal time, reported percentile mortality could not be estimated due to censoring as exact lethal time was unknown and the homogeneous nature of frequency values of the data for each concentration group. Censoring occurred because at the end of data collection insects were still alive; hence, actual lethal times were not observed for those concentrations and insecticides.

Relative potencies were computed to compare $P$. cruciferae mortality within two concentration groups $(1 \mathrm{X}-1.5 \mathrm{X}$ and $2 \mathrm{X}-4 \mathrm{X})$ for each treatment in terms of a standard conventional chemical treatment at 25,50 , and $75 \%$ (Table 4). The two groupings were used because mortalities between the two groups were significant across the experimental period. Also, in the PROC LIFETEST statement of survival analysis, intervals do not have to be the same. Moreover, it is desirable to make later intervals longer to include enough mortality values to give reliable estimates of hazard statistics (Allison 1995, van Belle et al. 2004). At $25 \%$, P. cruciferae mortality BotaniGard was the only treatment with comparable efficacy to Capture at $1 \mathrm{X}-1.5 \mathrm{X}$ concentration (Table 4$)$. At $2 \mathrm{X}-4 \mathrm{X}$ concentration, Surround, Neemix, and SpinTor treatments had relative efficacies equal to the conventional insecticide. However, BotaniGard with a relative potency ratio of 2 had a higher killing power than Capture (Table 4). At 50\% P. cruciferae mortality, the relative potencies of the ecorationals $(0.3-0.5)$ were lesser than 1.0 for Capture at both concentration groupings (Table 4). The $75 \%$ P. cruciferae mortality revealed that SpinTor was the only ecorational with potency at par with Capture, especially at the higher rate of $2 \mathrm{X}-4 \mathrm{X}$ (Table 4). All the insecticide treatments generally had better efficacies compared with the control (Table 4).

2003. Day 1. When P. cruciferae was exposed to the treatments, its mortality was higher for the chemical insecticides Helix XTra and Capture than the ecorational treatments (Table 5). Mortality ranged from 14.9 to $35.9 \%$ in the conventional insecticides and from 8.1 to $33.8 \%$ for SpinTor. Capture resulted in greater mortality compared with Helix XTra and SpinTor except at the $1 \mathrm{X}$ rate. Flea beetle mortality was generally greater in beetles exposed to Helix XTra than to SpinTor, although not at the $3.5 \mathrm{X}$ rate.

Day 2. P. cruciferae mortality from Helix XTra and Capture was greater than from SpinTor, BotaniGard, Surround, and Neemix (Table 5). P. cruciferae mortality ranged from 37.1 to $59.7 \%$ across Helix XTra treatments, from 29.2 to $62.7 \%$ for Capture, and from 29.2 to $52.1 \%$ for SpinTor treatments.

Day 3. P. cruciferae mortality ranged from 47.0 to $81.5 \%$ for Helix XTra and Capture and from 28.8 to $63.5 \%$ for SpinTor (Table 5 ). Mortality was greatest in the Helix XTra treatments compared with SpinTor treatments. Capture caused greater mortality effect on P. cruciferae than SpinTor.

Day 4. Capture and Helix XTra resulted in greater mortalities than SpinTor. Phyllotreta cruciferae mortality ranged from 55.5 to $89.1 \%$ after exposure to the conventional insecticide treatments Helix XTra and Capture and from 35.9 to $70.9 \%$ for SpinTor (Table 5). Capture and Helix XTra resulted in greater mortalities than SpinTor.

Day 5. Helix XTra and Capture resulted in 60.9$90.5 \%$ mortality. Mortality was lower for SpinTor, 46.5-72.9\% (Table 5).

Day 6. Mortality of P. cruciferae ranged from 55.6 to 94.1\% when adults were exposed to Helix XTra and Capture and from 36.1 to $77.7 \%$ for SpinTor (Table 5). Mortalities were consistently greater for Helix XTra $(77.8-94.1 \%)$ followed by Capture $(55.6-88.6 \%)$ and SpinTor (36.1-77.7\%).

Day 7. Mortality of P. cruciferae ranged from 73.9 to $100.0 \%$ after exposure to Helix XTra and Capture and from 39.3 to $95.5 \%$ for SpinTor (Table 5). P. cruciferae mortality was greater for the conventional insecticides compared with SpinTor, except at 1.5X and 3.5X rates.

Lethal times for 25,50 , and $75 \%$ mortality were estimated for two concentration groups, $1 \mathrm{X}-1.5 \mathrm{X}$ and $2 \mathrm{X}-4 \mathrm{X}$, for each insecticide tested against $P$. cruciferae (Table 6). The $\mathrm{LT}_{25}$ for P. cruciferae was $1 \mathrm{~d}$ for Helix XTra and Capture; $2 \mathrm{~d}$ for SpinTor; $4 \mathrm{~d}$ for Neemix and Surround, except for $2 \mathrm{X}-4 \mathrm{X}$ concentration group of Neemix; and $5 \mathrm{~d}$ for BotaniGard. Lethal time for $50 \%$ mortality at $1 \mathrm{X}-1.5 \mathrm{X}$ and $2 \mathrm{X}-4 \mathrm{X}$ concentration groups occurred at $2 \mathrm{~d}$ for Helix XTra, 3 and $2 \mathrm{~d}$ for Capture, 4 and $3 \mathrm{~d}$ for SpinTor, $6 \mathrm{~d}$ for Neemix, 5.5 and $5 \mathrm{~d}$ for Surround, and $7 \mathrm{~d}$ for BotaniGard. Lethal time for $75 \%$ flea beetle mortality in both concentration groups ranged from 4 and $3 \mathrm{~d}$ for Helix XTra to 5 and $4 \mathrm{~d}$ for Capture and SpinTor, and $7 \mathrm{~d}$ for Neemix and Sur- 
Table 5. Time-concentration-mortality response of $P$. cruciferae to ecorational and chemical insecticides on cotyledon canola, 2003

\begin{tabular}{|c|c|c|c|c|c|c|c|c|}
\hline \multirow{2}{*}{ Treatment } & \multirow{2}{*}{$\mathrm{DAT}^{a}$} & \multicolumn{7}{|c|}{ Insecticide concn $^{b}$} \\
\hline & & $1 \mathrm{X}$ & $1.5 \mathrm{X}$ & $2 \mathrm{X}$ & $2.5 \mathrm{X}$ & $3 \mathrm{X}$ & $3.5 \mathrm{X}$ & $4 \mathrm{X}$ \\
\hline & & \multicolumn{7}{|c|}{$\%$ mortality $^{c}$} \\
\hline BotaniGard ES & 1 & -4.1 & -5.4 & 3.9 & -5.7 & 5.2 & 0.0 & -2.7 \\
\hline Surround WP & 1 & -1.4 & -2.7 & 1.3 & -5.7 & 6.5 & 1.3 & -1.4 \\
\hline Neemix 4.5EC & 1 & -8.1 & -2.7 & 0.0 & -10.0 & 0.0 & -3.9 & -4.1 \\
\hline SpinTor 2 SC & 1 & 8.1 & 9.5 & 19.2 & 5.7 & 15.6 & 33.8 & 17.6 \\
\hline Capture 2EC & 1 & 17.6 & 27.0 & 35.9 & 31.4 & 35.1 & 33.8 & 33.8 \\
\hline Helix XTra & 1 & 27.0 & 14.9 & 24.4 & 24.3 & 31.2 & 20.8 & 28.4 \\
\hline Control $^{d}$ & 1 & 0.0 & 0.0 & 0.0 & 0.0 & 0.0 & 0.0 & 0.0 \\
\hline BotaniGard ES & 2 & -11.1 & -21.0 & -4.4 & -9.0 & 10.7 & 1.4 & -11.0 \\
\hline Surround WP & 2 & 0.1 & -16.0 & -4.4 & -3.0 & 9.3 & 6.9 & -3.0 \\
\hline Neemix 4.5EC & 2 & 1.4 & -16.0 & -7.3 & -14.0 & -2.7 & 1.4 & -9.0 \\
\hline SpinTor 2SC & 2 & 29.2 & 22.6 & 40.5 & 28.3 & 40.0 & 52.1 & 41.8 \\
\hline Capture 2EC & 2 & 29.2 & 37.1 & 59.4 & 47.7 & 62.7 & 60.3 & 59.7 \\
\hline Helix XTra & 2 & 51.4 & 37.1 & 37.6 & 56.7 & 57.3 & 39.7 & 59.7 \\
\hline Control & 2 & 0.0 & 0.0 & 0.0 & 0.0 & 0.0 & 0.0 & 0.0 \\
\hline BotaniGard ES & 3 & -1.5 & -27.0 & -28.0 & -28.0 & -6.6 & 1.4 & -8.0 \\
\hline Surround WP & 3 & 4.6 & -18.0 & -17.0 & -19.0 & -5.0 & 5.9 & 7.9 \\
\hline Neemix $4.5 \mathrm{EC}$ & 3 & 4.6 & -20.0 & -17.0 & -30.0 & -23.0 & -1.6 & -16.0 \\
\hline SpinTor 2SC & 3 & 28.8 & 35.7 & 53.4 & 44.4 & 49.1 & 56.7 & 63.5 \\
\hline Capture 2EC & 3 & 47.0 & 51.8 & 63.8 & 53.7 & 67.2 & 62.7 & 73.0 \\
\hline Helix XTra & 3 & 63.6 & 53.6 & 55.2 & 81.5 & 68.8 & 64.2 & 73.0 \\
\hline Control & 3 & 0.0 & 0.0 & 0.0 & 0.0 & 0.0 & 0.0 & 0.0 \\
\hline BotaniGard ES & 4 & -22.6 & -43.0 & -40.0 & -41.0 & -7.0 & -45.0 & -9.2 \\
\hline Surround WP & 4 & -1.9 & 14.2 & -22.0 & -2.1 & 43.8 & 7.1 & 43.6 \\
\hline Neemix 4.5 EC & 4 & -5.7 & -16.0 & -25.0 & -21.0 & -21.0 & -55.0 & -7.4 \\
\hline SpinTor 2 SC & 4 & 35.9 & 42.8 & 62.2 & 53.0 & 66.0 & 52.4 & 70.9 \\
\hline Capture 2 EC & 4 & 56.6 & 63.2 & 66.6 & 59.2 & 71.7 & 64.3 & 57.5 \\
\hline Helix XTra & 4 & 69.8 & 75.5 & 55.5 & 87.7 & 83.0 & 64.3 & 89.1 \\
\hline Control & 4 & 0.0 & 0.0 & 0.0 & 0.0 & 0.0 & 0.0 & 0.0 \\
\hline BotaniGard ES & 5 & -37.2 & -49.0 & -61.0 & -12.0 & -14.0 & -33.0 & -20.0 \\
\hline Surround WP & 5 & -4.7 & 14.6 & -43.0 & 7.1 & 9.2 & 18.8 & 37.5 \\
\hline Neemix 4.5 EC & 5 & -16.3 & -12.0 & -30.0 & 0.0 & -19.0 & -41.0 & -25.0 \\
\hline SpinTor 2 SC & 5 & 46.5 & 63.4 & 60.6 & 50.0 & 60.4 & 72.9 & 72.5 \\
\hline Capture 2 EC & 5 & 62.8 & 60.9 & 75.7 & 71.4 & 79.1 & 75.6 & 82.5 \\
\hline Helix XTra & 5 & 81.4 & 87.8 & 72.7 & 90.5 & 81.4 & 81.1 & 87.5 \\
\hline Control & 5 & 0.0 & 0.0 & 0.0 & 0.0 & 0.0 & 0.0 & 0.0 \\
\hline BotaniGard ES & 6 & -38.9 & -68.0 & -59.0 & -29.0 & -29.0 & -43.0 & -30.0 \\
\hline Surround WP & 6 & 13.9 & 3.1 & -19.0 & 3.1 & 19.9 & 36.7 & 37.9 \\
\hline Neemix 4.5 EC & 6 & 8.3 & -13.0 & -30.0 & -13.0 & -17.0 & -30.0 & -3.4 \\
\hline SpinTor 2 SC & 6 & 36.1 & 67.7 & 77.7 & 45.1 & 65.7 & 63.3 & 76.4 \\
\hline Capture 2 EC & 6 & 55.6 & 70.9 & 85.2 & 70.9 & 88.6 & 86.7 & 85.2 \\
\hline Helix XTra & 6 & 77.8 & 87.1 & 81.5 & 93.5 & 85.7 & 86.7 & 94.1 \\
\hline Control & 6 & 0.0 & 0.0 & 0.0 & 0.0 & 0.0 & 0.0 & 0.0 \\
\hline BotaniGard ES & 7 & 7.1 & -48.0 & -23.0 & -12.0 & 23.3 & -4.5 & -3.6 \\
\hline Surround WP & 7 & 21.4 & 17.2 & -18.0 & 23.1 & 33.3 & 59.1 & 60.7 \\
\hline Neemix 4.5 EC & 7 & 46.4 & 12.9 & 18.2 & 7.7 & 13.3 & -32.0 & 32.1 \\
\hline SpinTor 2 SC & 7 & 39.3 & 78.2 & 81.8 & 69.2 & 80.0 & 95.5 & 85.7 \\
\hline Capture 2 EC & 7 & 82.1 & 73.9 & 86.4 & 96.2 & 100.0 & 90.9 & 96.4 \\
\hline Helix XTra & 7 & 89.3 & 91.3 & 100.0 & 92.3 & 93.3 & 95.5 & 100.0 \\
\hline Control & 7 & 0.0 & 0.0 & 0.0 & 0.0 & 0.0 & 0.0 & 0.0 \\
\hline
\end{tabular}

${ }^{a}$ DAT, days after treatment.

${ }^{b}$ Insecticide concn, $1 \mathrm{X}$ the lowest label application rate equals BotaniGard, $0.51 \mathrm{ml} /$ liter; Surround, $3.06 \mathrm{~g} /$ liter; Neemix, 0.13 ml/liter; SpinTor, $0.13 \mathrm{ml} /$ liter; Capture, $0.04 \mathrm{ml} /$ liter; and Helix XTra, $52 \mathrm{mg} / 6.8 \mathrm{~g}$ seed.

${ }^{c}$ Flea beetle mortality was adjusted for natural mortality in the control treatment; a negative value indicates that natural mortality was greater in the control than the treatment.

${ }^{d}$ Control, water treatment; mortalities were $0 \%$ after adjusted control mortality.

round. For those groups of concentrations and insecticides with no lethal time for $\mathrm{LT}_{25}, \mathrm{LT}_{50}$, or $\mathrm{LT}_{75}$, the percentile mortalities could not be estimated due to censoring of data, as the exact lethal time was unknown for a concentration group.

Analyses and comparison of the efficacies of ecorationals to a standard conventional insecticide were done using the lethal times at two concentration groupings $(1 \mathrm{X}-1.5 \mathrm{X}$ and $2 \mathrm{X}-4 \mathrm{X})$ (Table 7$)$. Mortality of P. cruciferae at $25 \%$ showed that the relative potencies of the ecorationals were lesser than the standard Helix XTra at both concentration groups (Table 7). At 50\%, P. cruciferae mortality none of the ecorational insecticides had killing powers comparable with Helix XTra at both (1X$1.5 \mathrm{X}$ and $2 \mathrm{X}-4 \mathrm{X}$ ) concentrations (Table 7). SpinTor among the ecorationals had a higher efficacy, but this was still lower compared with the conventional insecticides. At $75 \%$, P. cruciferae mortality SpinTor, although had a lower potency compared with Helix XTra, its relative efficacy was at par with Capture at both concentration groupings (Table 7).

\section{Discussion}

Results from this study suggests that efficacy of insecticides tested against adult P. cruciferae was in the 
Table 6. Lethal time for ecorational and chemical insecticides at 25,50 , and $75 \%$ mortality of $P$. cruciferae, 2003

\begin{tabular}{|c|c|c|c|c|c|c|c|c|c|c|c|c|}
\hline \multirow{3}{*}{ Treatment } & \multicolumn{12}{|c|}{ Concn level $^{a}$} \\
\hline & \multicolumn{2}{|c|}{$1 \mathrm{X}-1.5 \mathrm{X}$} & \multicolumn{2}{|c|}{$2 X-4 X$} & \multicolumn{2}{|c|}{$1 \mathrm{X}-1.5 \mathrm{X}$} & \multicolumn{2}{|c|}{$2 X-4 X$} & \multicolumn{2}{|c|}{$1 \mathrm{X}-1.5 \mathrm{X}$} & \multicolumn{2}{|c|}{$2 X-4 X$} \\
\hline & Day $^{b}$ & $95 \% \mathrm{CI}^{c}$ & Day & $95 \% \mathrm{CI}$ & Day & $95 \% \mathrm{CI}$ & Day & $95 \% \mathrm{CI}$ & Day & $95 \% \mathrm{CI}$ & Day & $95 \% \mathrm{CI}$ \\
\hline & \multicolumn{4}{|c|}{$\mathrm{LT}_{25}{ }^{d}$} & \multicolumn{4}{|c|}{$\mathrm{LT}_{50}{ }^{d}$} & \multicolumn{4}{|c|}{$\mathrm{LT}_{75}{ }^{d}$} \\
\hline BotaniGard ES & 5 & $5-6$ & 5 & $4-5$ & 7 & ND & 7 & $6-7$ & ND & ND & ND & ND \\
\hline Surround WP & 4 & $3-4$ & 4 & ND & 5.5 & $5-6$ & 5 & ND & ND & ND & 7 & ND \\
\hline Neemix $4.5 \mathrm{EC}$ & 4 & $4-5$ & 5 & $4-5$ & 6 & $5-7$ & 6 & $6-7$ & 7 & ND & ND & ND \\
\hline SpinTor 2SC & 2 & $\mathrm{ND}^{e}$ & 2 & $1-2$ & 4 & $3-4$ & 3 & $2-3$ & 5 & $5-7$ & 4 & $4-5$ \\
\hline Capture 2EC & 1 & $1-2$ & 1 & ND & 3 & $2-3$ & 2 & ND & 5 & $4-6$ & 4 & $3-4$ \\
\hline Helix XTra & 1 & $1-2$ & 1 & ND & 2 & $2-3$ & 2 & ND & 4 & $3-4$ & 3 & $3-4$ \\
\hline Control $^{f}$ & 4 & $3-4$ & & & 5.5 & $5-7$ & & & ND & ND & & \\
\hline
\end{tabular}

${ }^{a} 1 \mathrm{X}-1.5 \mathrm{X}$ and $2 \mathrm{X}-4 \mathrm{X}$ concn groups, respectively, equal BotaniGard, 0.51-0.77 and 1.02-2.04 ml/liter; Surround, 3.06-4.59 and 6.12-10.70 g/ liter; Neemix, 0.13-0.19 and 0.25-0.51 ml/liter; SpinTor, 0.13-0.19 and 0.25-0.51 ml/liter; Capture, 0.04-0.06 and 0.08-0.16 ml/liter; and Helix XTra, 52-77 and 102-202 mg/6.8 g seed. The Kaplan-Meier method was used in estimating lethal times for each concentration group.

${ }^{b}$ Day, lethal time in days.

${ }^{c} \mathrm{CI}$, confidence interval.

${ }^{d}$ Lethal time required for 25,50 , and $75 \%$ mortality.

${ }^{e} \mathrm{ND}$, no data; lethal time for percentile and confidence interval could not be estimated because the frequency value was $<1$ and exact lethal time was unknown.

${ }^{f}$ Control, water treatment.

order of Helix XTra $>$ Capture $>$ SpinTor $>$ BotaniGard $>$ Neemix $>$ Surround. P. cruciferae mortality reached nearly $45 \%$ within $1 \mathrm{~d}$ of exposure to labeled rates of Helix XTra and Capture and $42 \%$ for SpinTor. Mortality of $P$. cruciferae remained low (i.e., $<40 \%$ ), even as treatment rates and exposure time increased for BotaniGard, Neemix, and Surround.

In $2002, P$. cruciferae mortality ranged from 33 to $58 \%$, from 44 to $78 \%$, and from 42 to $79 \%$ when exposed for $1 \mathrm{~d}$ to Helix XTra, Capture, and SpinTor, respectively. In 2003, P. cruciferae mortality ranged from 15 to $31 \%$, from 18 to $36 \%$, and from 8 to $34 \%$ for Helix XTra, Capture, and SpinTor, respectively. After $2 \mathrm{~d}$ of exposure in 2002 , mortality ranged from 54 to $78 \%$ for Helix XTra, from 60 to $94 \%$ for Capture, and from 66 to $92 \%$ for SpinTor. In 2003, P. cruciferae mortality

Table 7. Analysis and comparison of the efficacies of ecorationals to a standard chemical insecticide at 25, 50, and $75 \%$ mortality of $P$. cruciferae, 2003

\begin{tabular}{lcccccc}
\hline \hline \multirow{2}{*}{ Treatment $^{a}$} & \multicolumn{5}{c}{ Concn level $^{b}$} \\
\cline { 2 - 7 } & $1 \mathrm{X}-1.5 \mathrm{X}$ & $2 \mathrm{X}-4 \mathrm{X}$ & $1 \mathrm{X}-1.5 \mathrm{X}$ & $2 \mathrm{X}-4 \mathrm{X}$ & $1 \mathrm{X}-1.5 \mathrm{X}$ & $2 \mathrm{X}-4 \mathrm{X}$ \\
\hline & $\mathrm{LT}_{25 ; \mathrm{S}} / \mathrm{LT}_{25 ; \mathrm{T}}{ }^{c}$ & $\mathrm{LT}_{50 ; \mathrm{S}} / \mathrm{LT}_{50 ; \mathrm{T}}{ }^{c}$ & $\mathrm{LT}_{75 ;} / \mathrm{LT}_{75 ; \mathrm{T}}{ }^{2}$ \\
BotaniGard ES & 0.2 & 0.2 & 0.3 & 0.3 & $\mathrm{ND}^{d}$ & $\mathrm{ND}$ \\
Surround WP & 0.3 & 0.3 & 0.4 & 0.4 & $\mathrm{ND}$ & 0.4 \\
Neemix 4.5EC & 0.3 & 0.2 & 0.3 & 0.3 & 0.6 & $\mathrm{ND}$ \\
SpinTor 2SC & 0.5 & 0.5 & 0.5 & 0.7 & 0.8 & 0.8 \\
Capture 2EC & 1.0 & 1.0 & 0.7 & 1.0 & 0.8 & 0.8 \\
Helix XTra & 1.0 & 1.0 & 1.0 & 1.0 & 1.0 & 1.0 \\
Control $^{e}$ & 0.3 & 0.3 & 0.6 & 0.4 & $\mathrm{ND}$ & $\mathrm{ND}$ \\
\hline
\end{tabular}

${ }^{a}$ Treatment, Helix XTra the seed treatment was the standard chemical by which all treatments were compared.

${ }^{b} 1 \mathrm{X}-1.5 \mathrm{X}$ and $2 \mathrm{X}-4 \mathrm{X}$ concn groups, respectively, equal BotaniGard, 0.5l-0.77 and 1.02-2.04 ml/liter; Surround, 3.06-4.59 and 6.12-10.70 g/liter; Neemix, 0.13-0.19 and 0.25-0.51 ml/liter; SpinTor, 0.13-0.19 and 0.25-0.51 ml/liter; Capture, 0.04-0.06 and 0.08-0.16 ml/liter; and Helix XTra, 52-77 and 102-202 mg/6.8 g seed.

${ }^{c}$ Ratios of the lethal times of standard chemical to the treatments at 25,50 , and $75 \%$ mortality.

${ }^{d} \mathrm{ND}$, no data; ratio could not be estimated because the frequency values for lethal time estimation was $<1$ and exact lethal time was unknown.

${ }^{e}$ Control, water treatment. ranged from 37 to $60 \%$, from 29 to $63 \%$ and from 23 to $52 \%$ on exposure to Helix XTra, Capture, and SpinTor, respectively, for $2 \mathrm{~d}$. $P$. cruciferae mortality was generally from 47 to $100 \%$ after $3-7 \mathrm{~d}$ of exposure to the conventional treatments Helix XTra and Capture and from 29 to $100 \%$ for SpinTor. These results agree with the findings of McLeod et al. (2002) who observed $>40 \%$ mortality of eggplant flea beetle, Epitrix fuscula Crotch, after $2 \mathrm{~d}$ of exposure to leaf discs of eggplant (Solanum melongena L.) treated with chlorfenapyr, thiamethoxam, and spinosad. The effect of ecorational insecticides BotaniGard, Surround, and Neemix was very low, $<37 \%$ beetle mortality after $1 \mathrm{~d}$ of exposure and most often $<57 \%$ mortality after $2 \mathrm{~d}$ of exposure.

In 2002, the $\mathrm{LT}_{50}$ was $1 \mathrm{~d}$ for Capture, $2 \mathrm{~d}$ for SpinTor and BotaniGard, and $3 \mathrm{~d}$ for Neemix and Surround. In 2003 , lethal time for $50 \%$ mortality occurred between 2 and $3 \mathrm{~d}$ on exposure to Helix XTra and Capture and between 3 and $4 \mathrm{~d}$ for SpinTor, with $\mathrm{LT}_{50}$ values of 5-7 $\mathrm{d}$ on exposure to BotaniGard, Neemix, and Surround. The lethal time values in this study agree with the values of 1.8 and 3.6 d that McLeod et al. (2002) found for thiamethoxam and spinosad against eggplant flea beetle, Epitrix fuscula Crotch. Data on efficacy of BotaniGard in 2003 corresponds with that of Miranpuri and Khachatourians (1995) who observed $\mathrm{LT}_{50}$ values of 6.67 and $6.97 \mathrm{~d}$ for two strains, GK 2016 and SG 8702, respectively, of Beauveria bassiana against $P$. cruciferae. Also, data on BotaniGard in 2002 is consistent with the results of Miranpuri and Khachatourians (1995) and Kreutz et al. (2004) who found $>90 \%$ mortality and $\mathrm{LT}_{50}$ values of 5-7 d for P. cruciferae and spruce bark beetle, Ips typographus L., exposure to $B$. bassiana for $7 \mathrm{~d}$. Aging populations, genetic differences in susceptibility to insecticides and environmental factors affecting field populations in 2002 and 2003 are possible reasons why results differed between the two trials.

The relative potency analyses revealed that the conventional synthetic insecticides Helix XTra and Cap- 
ture were more effective than the ecorational treatments. SpinTor had the best efficacy and higher killing power against $P$. cruciferae among the ecorational insecticides. Although Insects can remain alive for up to $2 \mathrm{~d}$ after exposure to SpinTor (Thompson et al. 1999), it still can be an effective insecticide, because it causes paralysis and cessation of feeding within minutes of insects being exposed to the toxin (Thompson et al. 1999). This study indicates that SpinTor is an effective insecticide for crucifer flea beetle management, and it may serve as an alternative to chemical insecticides or in combination with seed treatments when flea beetle feeding injury extends beyond the protection period provided by conventional insecticides. Further studies will be necessary to determine how SpinTor compares with Capture and Helix XTra against P. cruciferae under field conditions.

\section{References Cited}

Abbott, W. S. 1925. A method of computing the effectiveness of an insecticide. J. Econ. Entomol. 18: 265-267.

Allison, P. D. 1995. Survival analysis using the SAS system: a practical guide. SAS Institute Cary, NC.

Barken, J.A.O., and J. D. Stark. 1997. Stage and age influence on the susceptibility of Coccinella septempunctata (Coleoptera: Coccinelidae) after direct exposure to Neemix, a neem insecticide. J. Econ. Entomol. 90: 1102-1105.

Berglund, D. R., and K. Mckay. 2002. Canola production. North Dakota State University Cooperative Extension Service Publication A-686. North Dakota State University Fargo, ND. (http://www.ext.nodak.edu/extpubs/plantsci/ crops/a686w.htm).

Blaney, W. M., M.S.J. Simmonds, S. V. Ley, J. C. Anderson, and P. L. Toogood. 1990. Antifeedant effects of azadirachtin and structurally related compounds on lepidopterous larvae. Entomol. Exp. Appl. 55: 149-160.

Brown, W. J. 1967. Notes on the extralimital distribution of some species of Coleoptera. Can. Entomol. 99: 85-93.

Burgess, L. 1977. Flea beetles (Coleoptera: Chrysomelidae) attacking rape crops in the Canadian Prairie provinces. Can. Entomol. 109: 21-32.

Canola Council of Canada. 2000. Final report on the pest management study conducted on behalf of the Canola Council of Canada. (http://www.canola-council.org/ pub_ipmsurvey2.html).

Canola Council of Canada. 2005. Canola industry growth and objectives. (http://www.canola-council.org/ ind_growth.html).

Eldelson, J. V., J. J. Magaro, and H. Browning. 1993. Control of insect pests on broccoli in southern Texas: a comparison between synthetic organic insecticides and biorational treatments. J. Entomol. Sci. 28: 191-196.

Gaugler, R. 2004. Nematodes (Rhabditida: Steinernematidae and Heterorhabditidae). (http://www.nysaes.cornell.edu/ ent/biocontrol/pathogens/nematodes.html).

Glogoza, P., M. McMullen, R. Zollinger, A. Thostenson, T. Dejong, W. Meyer, N. Schauer, and J. Olson. 2002. Pesticide use and pest management practices for major crops in North Dakota 2000. North Dakota State University Cooperative Extension Service Publication ER-79. North Dakota State University, Fargo, ND.

Hajek, A. E., R. S. Soper, D. W. Roberts, T. E. Anderson, K. D. Biever, D. N. Ferro, R. A. Leburn, and R. H. Storch. 1987. Foliar applications of Beauveria bassiana (Balsamo) for control of the Colorado potato beetle, Leptinotarsa de- cemlineata (Say) (Coleoptera: Chrysomelidae): an overview of pilot trial results from the northern United States. Can. Entomol. 119: 959-974.

Hokkanen, H.M.T., I. Menzler-Hokkanen, and T. M. Butt. 2003. Pathogens of oilseed rape pests, pp. 299-322. In D. V. Alford [ed.], Biocontrol of oilseed rape pests. Blackwell, Malden, MA.

Immaraju, J. A. 1998. The commercial use of azadirachtin and its integration into viable pest control programs. Pestic. Sci. 54: 285-289.

Kreutz, J., O. Vaupel, and G. Zimmerman. 2004. Efficacy of Beauveria bassiana (Bals.) Vuill. against the spruce bark beetle, Ips typographus L., in the laboratory under various conditions. J. Appl. Entomol. 128: 384-389.

Lamb, R. J. 1983. Phenology of flea beetle (Coleoptera: Chrysomelidae) flight in relation to their invasion of canola fields in Manitoba. Can. Entomol. 115: 1493-1502.

Lamb, R. J. 1984. Effects of flea beetles, Phyllotreta cruciferae (Coleoptera: Chrysomelidae), on the survival, growth, seed yield and quality of canola, rape and yellow mustard. Can. Entomol. 116: 269-280.

Lamb, R. J. 1988. Assessing the susceptibility of crucifer seedlings to flea beetle (Phyllotreta spp.) damage. Can. J. Plant Sci. 68: 85-93.

Lamb, R. J., and W. J. Turnock. 1982. Economics of insecticidal control of flea beetles (Coleoptera: Chrysomelidae) attacking rape in canola. Can. Entomol. 114: 827-840.

Marcus, R., and D. M. Eaves. 2000. Statistical and computational analysis of bioassay data. pp. 249-290. In A. Navon and K.R.S. Ascher [eds.], Bioassays of entomopathogenic microbes and nematodes. CABI Publishing, New York.

McLeod, P., F. J. Diaz, and D. T. Johnson. 2002. Toxicity, persistence and efficacy of spinosad, chlorfenapyr and thiamethoxam on eggplant when applied against the eggplant flea beetle (Coleoptera: Chrysomelidae). J. Econ. Entomol. 95: 331-335.

Miranpuri, G. S., and G. G. Khachatourians. 1995. Entomopathogenicity of Beauveria bassiana toward flea beetles, Phyllotreta cruciferae Goeze (Coleoptera: Chrysomelidae). J. Appl. Entomol. 119: 167-170.

Mordue (Luntz), A. J., M.S.J. Simmonds, S. V. Ley, W. M. Blaney, W. Mordue, M. Nasiruddin, and A. J. Nisbet. 1998. Action of azadirachtin, a plant allelochemical against insects. Pestic. Sci. 54: 277-284.

Perry, A. S., I. Yamamoto, I. Ishaaya, and R. Y. Perry. 1998. Insecticides in agriculture and environment. Springer, New York.

Putnam, L. G. 1977. Response of four brassica seed crop species to attack by crucifer flea beetle, Phyllotreta cruciferae. Can. J. Plant Sci. 57: 987-989.

SAS Institute. 2003. PROC user's manual, version 9.1 ed. SAS Institute, Cary, NC.

Schmutterer, H. 1990. Properties and potential of natural pesticides from the neem tree, Azadirachta indica. Annu. Rev. Entomol. 35: 271-297.

Sparks, T. C., G. D. Thompson, H. A. Kirst, M. B. Hertlein, J. S. Mynderse, J. R. Turner, and T. V. Worden. 1999. Fermentation-derived insect control agents-the spinosyns, pp. 171-188. In F. R. Hall and J. J. Menn [eds.], Biopesticides: use and delivery. Humana Press, Totowa, NJ.

Sparks, T. C., G. D. Crouse, and G. Durst. 2001. Natural products as insecticides: the biology, biochemistry and quantitative structure-activity relationships of spinosyns and spinosoids. Pest Manage. Sci. 57: 896-905.

Thacker, J.R.M. 2002. An introduction to arthropod pest control, 1st ed. Cambridge Univ. Press, Cambridge, United Kingdom. 
Thomas, P. 2003. Canola growers manual. Canola Council of Canada, Winnipeg, Manitoba, Canada.

Thompson, G. D., S. H. Hutchins, and T. C. Sparks. 1999. Development of spinosad and attributes of a new class of insect control products. (http:/ / ipmworld.umn.edu/ chapters/hutchins2.htm).

Thompson, G. D., R. Dutton, and T. C. Sparks. 2000. Spinosad-a case study: an example from natural products discovery programme. Pest Manage. Sci. 56: 696-702.

[USDArsqb] U.S. Department of Agriculture. 1998. Particle films: a new kind of plant protectant. Agric. Res. Mag. 46: 16-19. (http://www.ars.usda.gov/is/AR/archive/ nov98/film1198.htm).

[USDA-NASS] U.S. Department of Agriculture-National Agricultural Statistics Service. 2005a. Crop production 2004 summary. (http://usda.mannlib.cornell.edu/reports/nassr/ field/pcp-bban/cropan05.pdf).

[USDA-NASS] U.S. Department of Agriculture-National Agricultural Statistics Service. 2005b. Prospective plant- ings. (http:/ / usda.mannlib.cornell.edu/reports/nassr/ field/pcp-bbp/pspl0305.pdf).

[USDA-NASS] U.S. Department of Agriculture-National Agricultural Statistics Service. 2006. Prospective plantings. (http:// usda.mannlib.cornell.edu/reports/ nassr/field/pcp-bbp).

van Belle, G., L. D. Fisher, P. J. Heagerty, and T. Lumley. 2004. Biostatistics: a methodology for the health sciences, 2nd ed. Wiley, Hoboken, NJ.

Ware, G. W. 1989. The pesticide book, 3rd ed. Thompson Publications, Fresno, CA.

Weiss, M. J., P. McLeod, B. G. Schatz, and B. K. Hanson. 1991 The potential for insecticidal management of flea beetles (Coleoptera: Chrysomelidae) attacking canola. J. Econ. Entomol. 84: 1597-1603.

Received 19 September 2006; accepted 20 April 2007. 